\title{
Why Multinational Corporations Still Need to Keep It Local: Environment, Operations, and Ownership in the Hospitality Industry
}

Jie J. Zhang, Nitin R. Joglekar, and Rohit Verma

Introduction

While the goal of environmental sustainability offers positive global impact, its implementation must consider the inherent variations in the local environmental, social, and economic contexts. For instance, EnerNOC, a U.S. firm engaged in demand-side management of energy consumption, employs a business model that reduces aggregate energy demand during peak loads, and passes the savings to clients who respond to its conservation calls by reducing their energy demand (Healy 2007). EnerNOC has been successful in signing up key accounts including large corporations, governmental agencies, hotels, hospitals, and universities, yet its growth is limited by the ability of its sales force to engage individual building and facility managers to implement the demand-response practice (Tuttelman 2008). EnerNOC's experience shows that local variations in both the built environment and operational issues are central to the diffusion of sustainability practices. A wide community of users and environmental leaders recognize this connection, such as the USGBC (U.S. Green Building Council) through its LEED (Leadership in Energy and Environmental Design) rating system. Specifically, the LEED Existing Buildings: Operations \& Maintenance certification system (LEED EBOM) underlines how operations can stand in the way of realizing the potential of sustainable design and construction. We recognize this critical lens of local operations, and use it to assess the effectiveness of design parameters, construction standards, and operations in terms of consumption outcomes.

In the built environment, operations managers of individual sites face two major challenges in implementing sustainability practices. The first challenge involves difficulties in tracking environmental performance, because sites often lack consistent ways of measuring resource consumption or monitoring energy consumption patterns (Schleich and Gruber 2008). 
To this end, we develop operating measurements that reflect the contingent nature of environmental sustainability at the site level. With these measurements in place, corporations and facility managers can monitor outcomes of sustainability practices, thus providing feedback necessary for further improvement.

The second challenge lies in the conventional firm-centric view that overlooks the effect of diverging interests and performance-evaluation criteria of collaborating parties such as the building owner and the building operator. Delmas and Toffel (2008) show that within an organization, the difference in adopting environmental management practices relates to the receptivity of market and nonmarket pressures across functional departments such as corporate legal affairs and marketing departments. We argue that such varying receptivity is even more pronounced across firm boundaries. For example, in a hotel service chain, the central players, collaborating through franchise or management contracts or both, typically include the owner, who focuses on the development and management of the hotel real estate property, and the operator, who focuses on managing the daily hotel operations (i.e., guest services, facility management operations, and reservation systems). Consequently, the owner prefers practices that enhance the valuation of the physical assets, while the operator prefers practices that increase revenue-usually the base of royalty and management fees. In other words, due to their specialization and distinct reward structures, each service supply chain partner strives for a unique subset of business benefits (see chapter 11, this volume). Recognizing that supply chain partners do not share uniform interests in adopting sustainability practices, this chapter develops a theoretical framework to explicate the diverging interests along the chain and suggests potential economic and policy measures to align them.

We inform our arguments through an exploratory study of sustainability measures in a typical built environment-hotels-which is an ideal lab to research sustainability for three reasons:

1. Data availability-the contractual arrangement between hotel owner and hotel operator requires cost reporting on resources consumed, resulting in data that are difficult to gather in other built environments such as residences or commercial office buildings.

2. Industry commitment-major hotel chains identify sustainability as a strategic issue (Sherwyn 2010) for its potential to enhance brand image and reduce costs, creating strong momentum for sustainability innovations. 
3. Demonstration effect-guests satisfied with their green lodging experience might adopt some sustainability practices in their homes and workplaces, yielding positive externalities.

i To address the first challenge of measuring and comparing the performance of sustainability practices, we track 984 hotel sites across the United States over an eight-year period and construct a standardized measure of environmental sustainability based on resource efficiency. This sustainability measure is driven by two factors: an operating cost factor (OCF) and a consumer behavior cost factor (CBCF). We offer a comparative analysis of these two factors based on variations in five basic hotel characteristics: ownership structure, operating structure, level of urban development, type of guests, and regional ambient temperature. We illustrate that the values of these two factors vary systematically for each of the five characteristics.

- We use these differences to argue that it is possible-in fact desirable-to incorporate local variations into environmental policy changes aimed at improving sustainability in the built environment. For instance, effective environmental policy needs to address both the investment and operational issues related to ownership structure: the asset owner may choose to invest in solar panels, but this investment.requires the operator to change related energy and facility management routines to fully realize the return. However, the return on investment often only accrues to one party-utility savings for the owner in the case of solar panels. So there is little incentive for the operator to participate. A reverse situation is also possible. The asset owner's building architecture and energy equipment constrains how far the operator's efforts can go toward establishing a genuinely green brand reputation. Such situations are best described by the Prisoner's Dilemma with two players (Pruitt 1967). If both players commit to improvement, a win-win solution emerges; if both the players defect (i.e., cheat in the hope of private gain through the partner's commitment), a lose-lose scenario results. The threat to the cooperative efforts, hence the dilemma, arises from uncertainty of the partners' actions, in the presence of diverging performance goals. Unequal cooperation results in one side reaping rewards and the other becoming a "sucker." Clearly, no side wants to be the sucker.

Having provided an overview of our study, this chapter is organized as follows. We first describe the industry setting for our empirical study, then define and calculate the resource-efficiency-based environmental sustainability measures. Drawing from prior research on corporate motivations 
to adopt sustainability, we then develop a framework to identify the factors that influence the multiple agents in the built environment who have diverging goals, constraints, and planning horizons. We flesh out specific tradeoffs within this multi-agent commitment framework, suggest contracting and negotiation tools to bridge the incentive needs of various agents, and identify and close behavioral loopholes to accelerate the diffusion of sustainability practices in the built environment.

\section{The U.S. Hospitality Industry}

The U.S. hospitality industry, with buildings situated in diverse settings across the country, and with ongoing sustainability efforts of varying types and degrees, lends itself to study supply chain coordination and incentive structures. Each hotel site is both a real estate investment for hotel owners and a service and brand building opportunity for hotel operators. Multiple ownership and operating structure configurations are possible in this industry: owner operated (they own or lease the property), major chain operated (branded management), or nonbranded hotel management company operated. Further, the hospitality industry measures its performance in terms of return on assets (owner) and operating performance (operator), and both metrics are intimately linked with environmental sustainability practices. Table 5.1 illustrates the hospitality service supply chain for several common ownership structures and operating structures.

We conducted our empirical study on 984 U.S. hotel sites' annual operating statements from 2001 to 2008. These hotel sites are located across the United States, and represent all major U.S. hotel chains. We collected comparable information on all aspects of the hotel operations with an emphasis on operating expenses including consumption of fundamental resources such as electricity, water, and materials used as operating supplies. PKF Hospitality Research, an industry trend research firm that has tracked thousands of hotels for nearly seventy years, provided the data.

To resolve the first challenge listed previously of comparable data, we developed a measure to benchmark environmental sustainability in the hospitality industry based on the efficiency of hotels' use of fundamental resources to generate revenue (measured in revenue per available roomRevPAR). A wide range of resources are included: electricity; water and sewer; maintenance supplies; and laundry, linen, and supplies used in the rooms and food and beverage departments. This measure stemmed from analyzing the preceding panel dataset using exploratory factor analysis-a statistical method that analyzes the varying patterns of resource 
Table 5.1

Hospitality service supply chain players: Ownership and operating structure choices in the hotel industry

\begin{tabular}{llll}
\hline & Responsibilities & \\
\cline { 2 - 4 } $\begin{array}{l}\text { Types of owner- } \\
\text { ship and operating } \\
\text { structure }\end{array}$ & $\begin{array}{l}\text { Manage } \\
\text { property asset }\end{array}$ & $\begin{array}{l}\text { Manage } \\
\text { operations }\end{array}$ & $\begin{array}{l}\text { Set standards } \\
\text { and manage } \\
\text { distribution }\end{array}$ \\
\hline $\begin{array}{l}\text { Vertically integrated } \\
\begin{array}{l}\text { Franchisor/brand } \\
\text { operated }\end{array}\end{array}$ & Owner & Owner & Owner \\
$\begin{array}{l}\text { Professionally (non- } \\
\text { branded) managed }\end{array}$ & Owner & Brand & Brand \\
\hline
\end{tabular}

consumption and identifies primary drivers of resource efficiency in the sample. This analysis yielded one measure of environmental sustainability consisting of OCF that assigns large weights to electricity, water, sewer, and maintenance expenses, and $\mathrm{CBCF}$ that assigns large weights to expenses from laundry, linen, and supplies used in the rooms and food and beverage departments. Although all expenses are subject to influences from both management and guests, the expenses measured by the operating cost factor are more affected by managerial decisions, and the expenses measured by the consumer behavior cost factor are largely driven by guests' choices. We generate normalized factor scores to indicate how efficient the hotels are in using the resources for every unit of revenue generated-hotels that score below zero are more resource efficient than the average, and hotels that score above zero are less resource efficient. In summary, this two-factor measure of environmental sustainability is a consistent industry-wide measure for benchmarking sustainability performance by considering both internal environmental management choices and the guests' resource consumption behavior. We compare the factor scores across five basic hotel characteristics: ownership structure, operating structure, level of urban development, type of guests, and ambient temperature.

\section{Corporate Motivations to Adopt Sustainability}

A hotelier can expect several possible outcomes when she decides to build and operate sustainably. However, prior literature made conflicting predictions regarding the outcomes. Some of the earliest studies on corporate 
sustainability issues argue that environmental concerns reduce profit maximization (Friedman 1970). Later, Porter and van der Linde (1995) argued that a firm's pollution is often associated with wasted resources (material, energy, etc.), and that more stringent environmental regulation can stimulate green innovations that may offset pollution prevention costs. These debates generated a series of arguments around why a firm ought to invest in environmental protection efforts, and the possible outcomes. For instance, some scholars cite incentives such as near-term profitability gains through toxic waste prevention (King and Lenox 2002) and financial markets' positive response to environmental awards announced and confirmed by third parties (Klassen and McLaughlin 1996). Drawing on institutional theory, early work in this arena predicts an inevitable shift in corporate environmentalism in which sustainability goals become a way of organizational life (Hoffman and Ehrenfeld 1998, 73).

Various stakeholders (Freeman 1984) may also provide the motivation for building and operating green. Ambec and Lanoie (2008) conducted an extensive literature review and summarized the mechanisms through which firm characteristics may interact with various internal and external factors to influence economic performance. For instance, a firm may comply with government regulations, such as green procurement programs for EPA-designated products and services, and consequently enjoy increased revenue.

In spite of this extensive knowledge about a firm's motivation for sustainability, we have just begun to understand the sustainability motivations of organizations that are hybrid (i.e., neither market nor hierarchy) or extend across firm boundaries (e.g., supply chains) but connected through contractual "bridges" (Baker, Gibbons, and Murphy 2008). Prior research on the challenges of implementing strategic choices in individual operating units demonstrates the need for considering the multi-agent aspect of our study. For example, in the manufacturing context, researchers (Boyer and Lewis 2002; Boyer and McDermott 1999) found that a firm's personnel at different organizational levels can substantially disagree on strategic decisions. For instance, operations-level employees tended to rate investments in technology disproportionately higher than plant managers. Further, Boyer and Lewis (ibid.) present case evidence of significant inconsistencies in competitive priorities (i.e., cost, delivery, flexibility, and quality) across all levels of a firm's organizational chart. It is conceivable that similar inconsistencies exist across a firm's operating units and supply chain, with each unit optimizing its environmental performance according to its own set of priorities, constraints, and reward structure. 
Ownership Structure: Vertically Integrated vs. Management Outsourced Typically, the land or the building, or both, of a hotel may be owned or leased by the hotel owner, who then outsources the hotel operation to a management company via a long-term contract. Under this ownership structure, the hotel's operator often identifies capital expenditures aimed at increasing energy efficiency, but the owner must approve and fund the efforts, resulting in a split-incentive problem (Schleich and Gruber 2008). Evidence from the commercial real estate market (Fisher and Rothkopf 1989; Jaffe and Stavins 1994) suggests that neither the landlord (building owner), nor the tenant (the operating company) may have an incentive to invest in energy efficient equipment or services, although both parties may benefit from building value appreciation or the energy cost savings associated with increased energy efficiency. The landlord will not invest in energy efficiency if the investment costs cannot be passed on to the tenant. The tenant will not invest if the lease expires or terminates before recouping the energy efficiency investment costs. Sometimes, the hotel owner may choose to manage self-owned assets, resulting in a vertically integrated hotel where the owner is singly responsible for the costs and benefits of sustainability investment. Such integrated ownership structure requires the owner to have expertise in both real estate asset management and hotel service operations, but attenuates the split-incentive problem.

Figure 5.1a shows the two factor scores OCF and CBCF of the environmental sustainability measure for two groups of hotels based on the ownership structure distinction (vertically integrated vs. management outsourced). The figure suggests that the hotels that are vertically integrated score lower values in both OCF and CBCF, indicating a lower level of resource consumption per unit of revenue (i.e., higher resource efficiency). The resource efficiency lead of the vertically integrated hotels in figure 5.1a confirms the need to consider ownership structure and associated issues including split incentive when designing sustainability strategy and evaluating sustainability performance.

\section{Operating Structure: Franchisor/Chain Managed vs. Nonbranded Man-} agement Company

In the United States, about 70 percent of hotels are affiliated with branded chains such as Marriott, Hilton, or Wyndham. The benefits of branding include instant access to an established customer base, extensive reservation and marketing systems, and participation in dynamic processes such as strategy making (Bradach 1997). These benefits lead to synergy that enhances service uniformity and performance through innovation 
and learning across the sites (Barlow 2000). A branded hotel may be operated by the brand franchisor, a branded chain offering management services, or a nonbranded management company. On the one hand, in the franchisor/chain-managed hotels, by committing to the chain business model and investing in the mandated brand standards, the hotel owner faces potential hold-up problems that give the chain increased bargaining power (Unsal and Taylor 2009). On the other hand, the nonbranded hotel management company builds its core competences in hotel operations, and possesses no stake in the hotel's brand image. Because the choice of operating structure relates to the type of asset invested, the core competencies of agents, and the reward system, it affects a wide range of strategic decisions, including sustainability. Figure $5.1 \mathrm{~b}$ shows the factor scores-OCF and CBCF-for two groups of hotels: those managed by a franchisor or hotel chain company vs. those managed by nonbranded hotel management companies. The results show that franchisor/chainmanaged hotels are more resource efficient in both factors. This may indicate that the franchisor and the chain operators have stronger incentive to increase resource efficiency due to their larger stake (e.g., in terms of brand equity) in the operation. Therefore, operating structure and its associated incentive issues are important considerations in the decisions to build and operate green.

\section{Location: Urban vs. Rural/Suburban}

The process of urbanization intertwines with people moving into cities to seek economic opportunities. So we draw the distinction between urban and rural/suburban areas by the population density-areas that have 1,000 and more persons per square kilometer are considered urban, while areas that have less than 1,000 persons per square kilometer are considered rural/suburban. Higher population density accompanies increased per capita energy consumption and extensive modification of the natural environment (McDonnell and Pickett 1990). Consequently, hotels in various locations may face varying resource and environmental pressures. For instance, high prices for gas and electricity and resource shortage (such as brownouts and water bans) are more likely to affect hotels located in urban areas. Sustainable development strategies need to reflect the varying resource constraints across locations. Figure $5.1 \mathrm{c}$ shows a comparison of the two environmental sustainability factor scores for hotels located in urban areas and those located in rural or suburban areas.

The graph shows that relative to their rural/suburban counterparts, the hotels in an urban environment consume fewer resources measured by 
operating cost factor (e.g., maintenance and utilities) but consume more measured by the consumer behavior cost factor (e.g., supplies for rooms and food and beverage departments) per unit of revenue generated. Because the factor scores reflect cost-based resource efficiency, either higher revenue or lower total cost of consumption may contribute to these differences. On the revenue side, urban hotels tend to charge higher prices for their services than their rural/suburban peers, resulting in a larger revenue base for urban hotels. On the consumption cost side, opposite forces are at play: for OCF-driven decisions, higher resource scarcity in the urban areas may provide a stronger incentive for hotel managers to improve their resource efficiency, while perceived abundant resources may support wasteful processes and result in lower efficiency in the rural/suburban hotel sites. As for the CBCF, since the hotels have limited control over their guests' consumption behavior, the higher resource prices in urban areas dominate and result in lower consumer behavior-related resource efficiency in the urban areas. Therefore, the varying effects of locationbased constraints must be considered in the decision-making process for sustainability.

\section{Type of Guests Served: Transient vs. Group}

Some hotel guests travel for leisure (creating a "transient" income stream in hospitality industry terminology) and others for business purposes (creating a "group" income stream). Although almost identical in terms of the service delivery processes, these two types of income streamstransient and group-may involve different decision-making processes by the guests. For example, a tourist is likely to choose a hotel based on her budget, personal experience, and family consideration, while the same person on a business trip must consider her company travel policy in choosing a hotel. In other words, while transient income results from the individual guest's personal value system, group income is jointly determined by personal and institutional choices. One industry trend serves as a good indication of how these institutional and personal choices may interact. Increasingly, corporations are favoring hotels that promote efforts toward environmental sustainability. A recent survey shows that 65 percent of corporate travel executives responsible for over $\$ 10$ million in annual travel budgets are in various stages of implementing green business travel guidelines (HSPI 2011). It stands to reason that hotels that derive more income from group business and conference activities have stronger incentive to adopt sustainability initiatives. The types of guests served closely relate to the hotel property type, that is, the facilities 


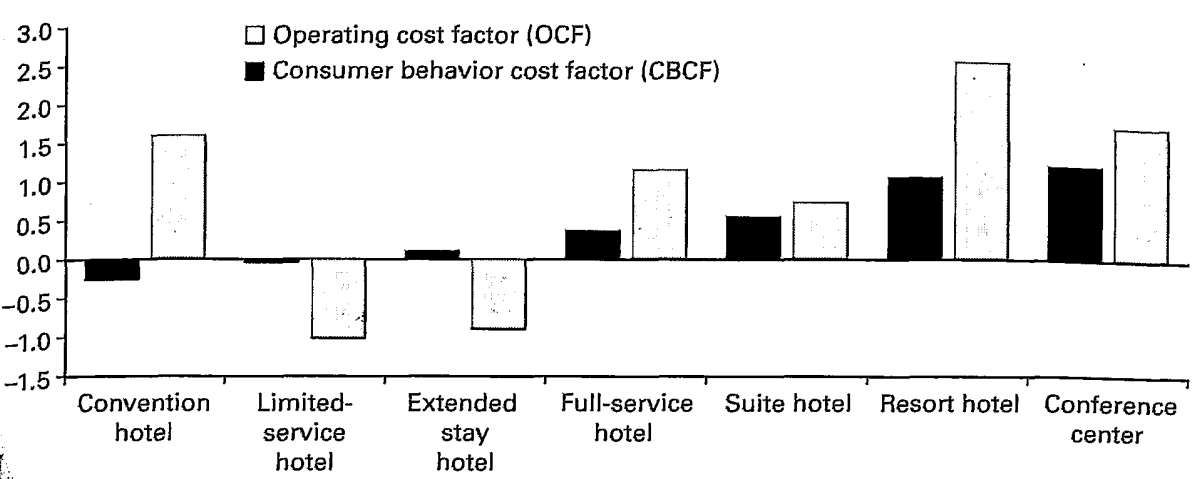

Figure 5.2

Property type and environmental sustainability factor scores in the hotel sector

and amenities available to support certain guest activities. Our dataset contains seven types of hotel properties: conference center, resort hotel, full-service hotel, limited-service hotel, suite hotel, convention hotel, and extended-stay hotel. (The glossary details the definition for each hotel type.) Figure 5.2 depicts how the two factor scores of the environmental sustainability measure vary across different hotel types.

The results show that resource consumption correlates positively with the level of service the hotels provide-resort and conference hotels consume more resources along OCF and CBCF, while the limited-service and extended-stay hotels consume much less in both factors. At one end, resort and conference hotels provide extensive amenities such as pools/ saunas/health clubs, restaurants, shops, and ballrooms, and may be a destination in their own right. At the other extreme are limited-service hotels that provide only essential lodging services and where guests tend to engage in activities outside the hotel property boundary, and thus use fewer resources on the hotel premises.

\section{Regional Ambient Temperature: Hot vs. Cold}

The aggregate warming at the global level coupled with increasingly volatile local weather conditions pose great challenges for hotels trying to predict future energy needs and balance guest comfort and energy requirements. Both the energy sources currently used to provide cooling and heating and potential or newly developed alternative energy sources are closely connected with the local natural resources and environment. For 


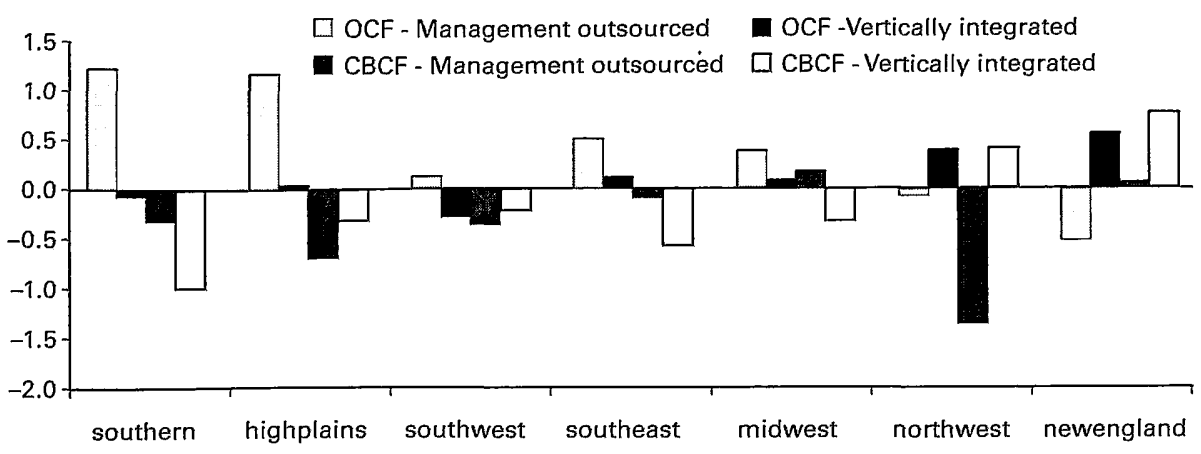

\section{Figure 5.3}

Environmental sustainability factor scores for the hotel sector (OCF and CBCF) by climate zone: owner managed vs. other managed

instance, hotels in the U.S. Southwest face increasing pressure from water shortage problems due to the dry climate, but also are situated in an ideal climate to take advantage of solar energy innovations. Forming strategic relationships with appropriate energy and energy solution suppliers then becomes an important strategy for hotels. A sound environmental sustainability strategy for a hotel site must therefore consider the markedly different long-term resource use patterns and potential scenarios. Figure 5.3 depicts the operating cost factor scores and consumer behavior cost factor scores across different climate zones of the vertically integrated hotels and management outsourced hotels in our sample.

Figure 5.3 identifies large variations in environmental sustainability as measured by OCF and CBCF across climate zones. Further, these two factors exhibit different variation patterns: specifically, vertically integrated hotels display a much smaller variability in OCF (dark solid bars in the graph) across climate zones.

\section{Paired-Case Comparisons}

We then conducted a series of $t$-tests to validate the intuitions gleaned from the graphs presented earlier (i.e., figures 5.1-5.3). The $t$-test assesses whether the means of two groups are statistically different from each othex. For each of the five hotel characteristics, we divide the sample into two groups and compare the means of the OCF score and the CBCF score. For example, we first divide the sample into two groups based on the ownership structure and use "O" to represent the group of hotels under owner 
management and use " $T$ " to represent the group of hotels where management is outsourced. In addition, we compared subgroups by considering combinations of multiple characteristics, such as hotels in urban locations under owner management (UO) vs. urban hotels where management is outsourced (UT). Table 5.2 summarizes these paired-case $t$-test results. All the comparisons in table 5.2 are statistically significant at the 0.05 level.

To summarize, we provide evidence on the contingent nature of sustainability practices by comparing the measured environmental sustainability of the hotels in our sample along local site variations including ownership structure (vertically integrated vs. management outsourced), operating structure (franchisor/chain managed vs. non-branded management), type of guests (transient vs. group), location (urban vs. rural/suburban), and ambient temperature (hot vs. cold). The graphs (figures 5.1-5.3) illustrate

\section{Table 5.2}

The $t$-test summary of environmental sustainability factor score comparisons across basic hotel characteristics ${ }^{1}$

\begin{tabular}{cll}
\hline & $\mathrm{OCF}$ & $\mathrm{CBCF}$ \\
\hline Owner-managed (O) vs. Outsourced (T) & $\mathrm{O}>\mathrm{T}^{2}$ & $\mathrm{O}>\mathrm{T}$ \\
Franchisor/chain (F) vs. Nonbranded (M) & $\mathrm{F}>\mathrm{M}$ & $\mathrm{F}>\mathrm{M}$ \\
$\quad$ Franchisor/chain O vs. T & $\mathrm{FO}>\mathrm{FT}$ & $\mathrm{FO}>\mathrm{FT}$ \\
$\quad$ Nonbranded O vs. T & $\mathrm{MO}<\mathrm{MT}$ & $\mathrm{MO}<\mathrm{MT}$ \\
Rural/suburban (R) vs. Urban (U) & $\mathrm{R}<\mathrm{U}$ & $\mathrm{R}>\mathrm{U}$ \\
$\quad$ Rural/suburban O vs. T & $\mathrm{RO}>\mathrm{RT}$ & $\mathrm{RO}>\mathrm{RT}$ \\
$\quad$ Urban O vs. T & $\mathrm{UO}>\mathrm{UT}$ & $\mathrm{UO}=\mathrm{UT}$ \\
Ambient temperature Hot (H) vs. Cold (C) & $\mathrm{H}<\mathrm{C}$ & $\mathrm{H}>\mathrm{C}$ \\
$\quad$ Hot O vs. T & $\mathrm{HO}>\mathrm{HT}$ & $\mathrm{HO}>\mathrm{HT}$ \\
Cold O vs. T & $\mathrm{CO}<\mathrm{CT}$ & $\mathrm{CO}<\mathrm{CT}$ \\
Full Service (S) vs. Limited (L) & $\mathrm{S}<\mathrm{L}$ & $\mathrm{S}<\mathrm{L}$ \\
Full Service O vs. T & $\mathrm{SO}<\mathrm{ST}$ & $\mathrm{SO}<\mathrm{ST}$ \\
Limited Service O vs. T & $\mathrm{LO}>\mathrm{LT}$ & $\mathrm{LO}>\mathrm{LT}$ \\
\hline
\end{tabular}

1. The letters in the parentheses are shorthand for the hotel site characteristics. For example, FO represents a hotel that is owned and managed by a franchisor/chain; while FT indicates a hotel for which the owner hires a franchisor/ chain as the operator.

2. The ">" sign indicates better environmental sustainability as measured by the factor scores. 
the distinct patterns in the measured environmental sustainability. The $t$-test comparisons statistically validate the intuitions from the graphs. (Readers may refer to Zhang, Joglekar, and Verma (2012) for statisti$\mathrm{cal}$ analyses that quantify the individual effects in the presence of other sources of variability such as scale of operations, market segment, and the overall economic cycle.) These analyses show that a multilevel theoretical approach is necessary to illuminate the various modes of inter-firm collaborations and intra-firm coordination, especially for organizations with complex distributed operations carrying distinct local characteristics.

\section{Managerial and Policy Implications}

A simple conclusion is that we observe considerable heterogeneity in the operating cost and consumer behavior cost components of environmental sustainability regarding local variations. Thus, a uniform policy aimed at coordinating multi-agent commitment may not be the most effective way to improve resource efficiency. That is, even if we draw upon the firm-centric view of the stakeholder-driven strategy formation process, we cannot attempt a unified implementation of strategies. The variation in sustainability performance associated with differences in asset ownership, operating structure, location, and so on, requires a contingent approach that explicitly considers the diverging interests of multiple agents and varying contextual factors.

\section{Multi-agent Collaboration}

A second and equally important implication of our research is about how hotel owners and operators decide on increasing resource efficiency. We focus on the dyadic relationship surrounding an asset: the hotel property owner and hotel operator. Nearly one third of the built environment in our hospitality industry dataset is owned by real estate investors (individuals and groups-e.g., corporations, LLCs). Generally, they maximize a combination of their rents and their assets' long-term value. Organizationally, these owners may be absentee landlords with little time or inclination to understand and manage the day-to-day operations and the challenges. These properties typically are managed by large hotel chains that are experts in service operations. These operators understand and track the operating cost factor, as well as the guest behavior that drives resource consumption.

It is clear that these two parties need to work collaboratively toward increasing resource efficiency. For instance, the installation of solar panels to heat water requires approval and funding from the property owner. 
Yet merely adding solar panels usually is not enough to realize cost savings, because the peak generation of energy mid-day does not coincide with the peak demand for hot water, typically in the morning. The hotel operator may decide to change the housekeeping and laundry schedule to take advantage of the abundant hot water during the middle of the day. This is easier to achieve when the asset ownership and operating tasks are governed by a single entity such as in vertically integrated hotels.

\section{Incentive Design}

The ownership of a hospitality physical asset increasingly is separated from its operator, and the economic and social interests of the asset owner and the operator are rarely aligned. The Prisoner's Dilemma is a wellknown metaphor used in psychological, sociological, and economic research to model situations of social conflict between two or more interdependent actors (Luce and Raiffa 1957; Janssen 2008; Pruitt 1967). The essence of the dilemma is that each individual actor has an incentive to act according to competitive, narrow self-interests even though, in general, all actors receive greater payoffs if they collectively cooperate. We follow the structure outlined by Cable and Shane (1997) to explain the underlying tensions in the Prisoner's Dilemma in figure 5.4.

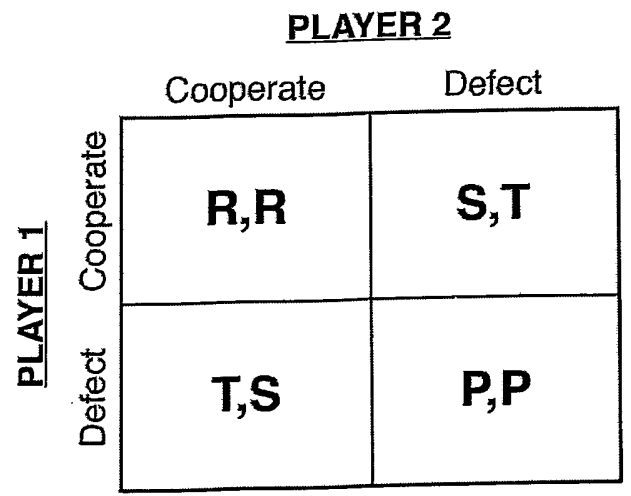

PAYOFFS: Iemptation $>$ Reward $>$ Punishment $>$ Sucker

Figure 5.4

General $2 \times 2$ payoff matrix for the classical two-person Prisoner's Dilemma (Cable and Shane 1997) 
Cable and Shane (1997) point out that "consistent with past research (e.g., Axelrod and Dion 1988), the payoffs for each actor are dictated by the strategy adopted by the other actor and follow the payoff structure $\mathrm{T}>\mathrm{R}>\mathrm{P}>\mathrm{S}$, in which $\mathrm{T}$ represents the temptation of extra payoff from defection, $R$ represents the reward for mutual cooperation, $P$ signifies the penalty for mutual defection, and S represents the 'sucker's' payoff (the penalty for cooperating while the other actor furtively defects, unknown to the sucker). This payoff structure illustrates the Dilemma's conceptual value by highlighting the conflict between individual and collective rationality." In the built environment, such dilemmas have been examined for problems such as demand-and-supply mismatch driven by cyclical markets (Kummerow 1999). Prisoner's dilemmas have also been identified in the diffusion of environmental practices in settings such as coastal zone and watershed management (Reddy 2000; O’Riordan 1993, 3-36). In figure 5.5, we outline the key factors that drive the commitment of the asset owner and operator based on the hospitality site database.

We follow Cable and Shane (1997) in identifying these factors:

- Site-specific alignment and information sharing: Site-specific variation is evident in table 5.2 based on differences in ownership structure, operating alignment between actors drives the nature and extent of their information exchange.

- Time horizon: The various actors have different planning horizon needs. A real estate investor's time horizon is typically longer than that of a corporate group trying to make operational improvements. The investor's time horizon is driven by tax laws, and the nature of investors in real estate investment trusts (REITs) - typically three to thirty years. A corporate group tends to set planning horizons based on organizational needs that generally range between three and thirty months. In the hospitality industry, the prevailing contract types are revenue-based franchising contracts and profit-based management contracts, whose inherent short-term performance bias discourages sustainability investments in the delayedpayoff and high-upfront-cost scenarios. Assigning the sustainability investment ownership to the contractual party that has most to gain is one way to address the split incentive (Mathewson and Winter 1985). For example, new contracting mechanisms can be designed to tie the cost and payoff of environmental sustainability investments with the life of the investment instead of the contractual relationship. Government guarantees or third-party investors willing to take the risks (and share the profits) from uncertainty may be the broker or even hold the ownership to the inyestment-an arrangement analogous to home mortgages. 


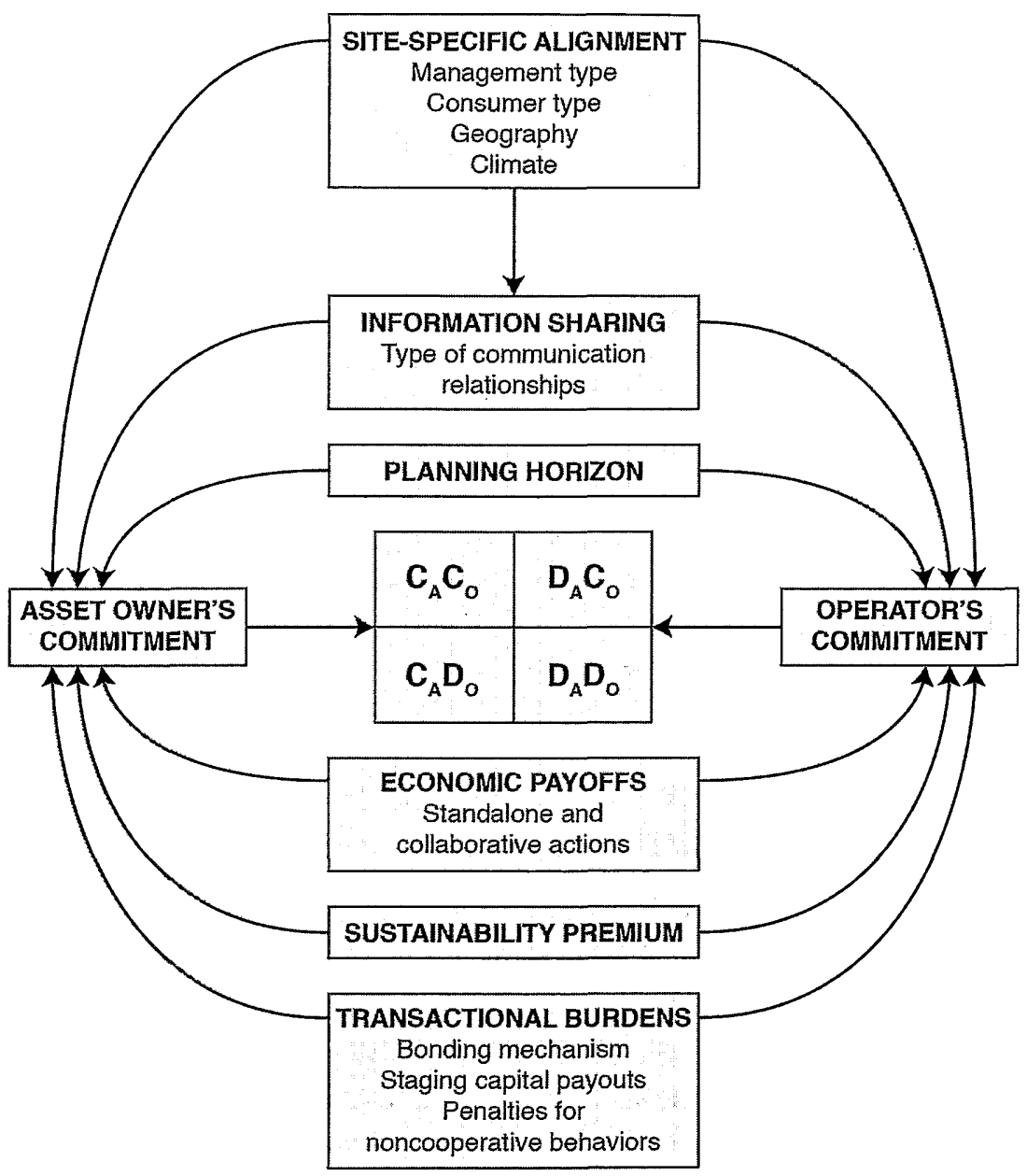

$C_{A}$ : Asset owner cooperates

$D_{A}$ : Asset owner defects
$C_{0}$ : Operator cooperates

$\mathbf{D}_{\mathrm{0}}$ : Operator defects

Figure 5.5

A framework comparing asset owner and operator commitment in the hotel sector 
- Economic payoffs: The nature of economic payoff depends on the resource-savings technologies and the business processes affected by the owner's and operator's commitment to increasing resource efficiency. Often the payoff requires upfront investment along with ongoing operating commitments such as investment in terms of staff and working capital. Certain technologies, such as insulation, geothermal, and solar units may be eligible for government tax credits based on their sustainability impact. Other technologies such as an environmental management system may also contribute to sustainability, but are often ineligible for the tax credits. Life-cycle analysis (LCA) of these technologies evaluates the cost and payoff comprehensively and therefore should be the basis of policy or tax incentives.

- Transactional burdens: The behavior of individual actors is affected not only by contractual arrangements that bind the actors, but also by the size and schedule of payoff as well as penalties for noncompliance with the contractual arrangements. It is important to realize that parties outside the contractual relationship, such as the hotel guests, may actively affect the payoff of the sustainability investment through their influence on the consumer behavior cost factor (Zhang, Joglekar, and Verma 2011).

We recognize that our framework holds many limitations. It considers only two key players-owner and operator-out of the many stakeholders in the hotel service supply chain. There is significant difficulty in measuring in practice the key constructs depicted in figure 5.5. We assume a single-shot game set-up, yet the agents often need to make repeated decisions, such that their brand image influences the observers' assessments. Fleshing out such a framework should offer useful solutions for built environment settings where sustainability practices are difficult to instill.

\section{Policy Implications for the Built Environment}

We posit that instituting public policy and program changes may prompt the hotel property owner and operator to commit to sustainability practices and stimulate the diffusion of environmental sustainability practices in this industry. First, to facilitate information exchange and comparison, it may be more effective for government agencies such as the EPA to recognize the contingent nature of performance across sites in future standards and programs. For example, the EPA's Portfolio Manager in its current version, which ranks all U.S. hotels in the same group, misses the opportunity to identify local sustainability champions and to help spread green practices. The EPA could better achieve its goals by customizing its 
approach and creating programs that serve specific types of hotel sites based on ownership, operating structure, guest type, location, and ambient weather conditions. Moreover, two kinds of monitoring mechanisms are needed. One would ensure that the contractual parties fulfill their commitments. A system similar to the financial accounting reporting system would likely work for environmental reporting. The other monitoring mechanism would ensure that the full potential of the design and construction standards is actually realized in operation. This monitoring system will rely on the "smart" technologies emphasizing sensing and real-time energy management being deployed in the built environment. Movement in this positive direction is also reflected in the changes proposed in the 2012 LEED standards, which include resource metering and data sharing.

\section{Conclusion}

As the world we live in becomes flatter and hotter, it is increasingly important to identify sustainability solutions sensitive to local variations and for policies to support those solutions. In this chapter, we offer preliminary evidence on how these local variations may affect sustainability performance in a typical built environment-the hospitality industryand present the policy implications of these local variations.

By focusing on two primary drivers of resource consumption-operational choices and customer behavior-we obtain an industry-wide measure of sustainability performance. On the operational side, information for evaluating and selecting sustainability initiatives is lacking due to the paucity of metrics for resource consumption and efficiency. However, the advent of the "smart hotel" that utilizes sensor and automation technologies to acquire real-time information promises more detailed and sensitive metrics to be constructed using an approach similar to ours. On the consumer behavior side, the sociological development in green marketing (Prakash 2002) and consumer receptivity to sustainable products and services (Shrum, McCarty, and Lowrey 1995) are key issues. Consumer behavior research experiments coupled with discrete choice analysis (McFadden 1974; Verma, Thompson, and Louviere 1999) can be designed to study the factors influencing customer choice.

We show that systematic differences in sustainability performance exist across basic hotel characteristics ranging from ownership structure to local weather conditions. These differences informed our framework for understanding the manner in which multiple agents can cooperate 
and commit to sustainability practices. Future research can address the complexity involved in this framework in two complementary directions: game theoretical analysis followed by empirical validation highlights this framework's salient effects and relationships, which are briefly explored in the "incentive design" section of this chapter; simulation using system dynamics (Forrester 1971) tools is another fruitful research direction. A multi-agent approach (for example, Swaminathan, Smith, and Sadeh 1998) could be especially useful in elucidating the relationships among supply chain partners, and significantly enrich contexts where key effects unfold.

\section{Acknowledgments}

The authors sincerely thank the Cornell Center for Hospitality Research (CHR) and PKF Hospitality Research (PKF-HR) for their invaluable industry insights and data support. The discussions at the CHR 2009 and 2010 Sustainability Roundtables greatly enriched the ideas in this chapter. Any opinions, findings, and conclusions or recommendations expressed in this chapter are those of the authors and do not necessarily reflect the views of CHR or PKF-HR. An initial version of this research was presented at the 2010 Constructing Green Conference hosted by Erb Institute at the University of Michigan, Ann Arbor. We gratefully acknowledge feedback from the conference participants.

\section{References}

Ambec, Stefan, and Paul Lanoie. 2008. Does it pay to be green? A systematic overview. Academy of Management Perspectives 22 (4): 45-62.

Axelrod, Robert, and Douglas Dion. 1988. The further evolution of cooperation. Science 242 (4884): 1385-1390.

Baker, George P., Robert Gibbons, and Kevin J. Murphy. 2008. Strategic alliances: Bridges between "islands of conscious power." Journal of the Japanese and International Economies 22 (2): 146-163.

Barlow, James. 2000. Innovation and learning in complex offshore construction projects. Research Policy 29 (7-8): 973-989.

Berzon, Alexandra, and Kris Hudson. 2011. Marriott loses trendy Waikiki hotel as owner changes locks overnight. The Wall Street Journal, August 29, Business.

Boyer, Kenneth K., and Marianne W. Lewis. 2002. Competitive priorities: Investigating the need for trade-offs in operations strategy. Production and Operations Management 11 (1): 9-20. 
Boyer, Kenneth K., and Christopher McDermott. 1999. Strategic consensus in operations strategy. Journal of Operations Management 17 (3): 289-305.

Bradach, Jeffrey L. 1997. Using the plural form in the management of restaurant chains. Administrative Science Quarterly 42 (2): 276-303.

Cable, Daniel M., and Scott Shane. 1997. A prisoner's dilemma approach to entrepreneur-venture capitalist relationships. Academy of Management Review 22 (1): 142-176.

Delmas, Magali A., and Michael W. Toffel. 2008. Organizational responses to environmental demands: Opening the black box. Strategic Management Journal 29 (10): 1027-1055.

Fisher, Anthony C., and Michael H. Rothkopf. 1989. Market failure and energy policy: A rationale for selective conservation. Energy Policy 17 (4): 397-406.

Forrester, Jay W. 1971. World dynamics. Cambridge, MA: Wright-Allen Press.

Freeman, R. Edward. 1984. Strategic management: A stakeholder approach. Lanham, MD: Pitman.

Friedman, Milton. 1970. The social responsibility of business is to increase its profits. The New York Times Magazine. September 13: 32.

Healy, Tim. 2007. EnerNOC chairman's letter to shareholders. Annual Report: 5-9. http://www.shareholder.com/visitors/dynamicdoc/document.cfm?documenti $\mathrm{d}=2424 \&$ companyid $=$ ENOC $\&$ page $=1 \&$ pin $=537039.828 \&$ language $=E N \&$ resize three $=$ yes \& scale $=100 \&$ zid $=($ accessed April 17, 2010).

Hoffman, Andrew J., and John R. Ehrenfeld. 1998. Corporate environmentalism, sustainability, and management studies. In Sustainability: Strategies for industry. The future of corporate practice, ed. Nigel J. Roome, 55-73. Washington, DC: Island Press.

HSPI. 2011. MindClick SGM Study: Green corporate business travel to make strong impact on hotel brand selection. Hospitality Sustainable Purchasing Index. http://www.hspiconsortium.com/press-releases/mindclick-sgm-study-greencorporate-business-travel-to-make-strong-impact-on-hotel-brand-selection/ (accessed September 8, 2011).

Jaffe, A. B., and R. N. Stavins. 1994. The energy-efficiency gap. Energy Policy 22 (10): 804-810.

Janssen, Marco A. 2008. Evolution of cooperation in a one-shot Prisoner's Dilemma based on recognition of trustworthy and untrustworthy agents. Journal of Economic Behavior \&o Organization 65 (3-4): 458-471.

King, Andrew A., and Michael J. Lenox. 2002. Exploring the locus of profitable pollution reduction. Management Science 48 (2): 289-299.

Klassen, Robert D., and Curtis P. McLaughlin. 1996. The impact of environmental management on firm performance. Management Science 42 (8): 1199-1214.

Kummerow, Max. 1999. A system dynamics model of cyclical office oversupply. Journal of Real Estate Research 18 (1): 233-256. 
Luce, R. Duncan, and Howard Raiffa. 1957. Games and decisions: Introduction and critical survey. New York: Wiley.

Mathewson, G. Frank, and Ralph A. Winter. 1985. The economics of franchise contracts. Journal of Law or Economics 28 (3): 503-526.

McDonnell, Mark J., and Steward T. A. Pickett. 1990. Ecosystem structure and function along urban-rural gradients: An unexploited opportunity for ecology. Ecology 71 (4): 1232-1237.

McFadden, Daniel. 1974. Conditional logit analysis of qualitative choice behavior. In Frontiers in econometrics, ed. Paul Zarembka, 105-142. New York: Academic Press.

O'Riordan, T. 1993. The politics of sustainability. In Sustainable environmental economics and management: Principles and practice, ed. R. Kerry Turner, 3-36. Hoboken, NJ: John Wiley \& Sons.

Porter, Michael E., and Claas van der Linde. 1995. Toward a new conception of the environment-competitiveness relationship. Journal of Economic Perspectives 9 (4): 97-118.

Prakash, Aseem. 2002. Green marketing, public policy and managerial strategies. Business Strategy and the Environment 11 (5): 285-297.

Pruitt, Dean G. 1967. Reward structure and cooperation: The decomposed prisoner's dilemma game. Journal of Personality and Social Psychology 7 (1): 21-27.

Reddy, V. Ratna. 2000. Sustainable watershed management: Institutional approach. Economic and Political Weekly 35 (38): 3435-3444.

Schleich, Joachim, and Edelgard Gruber. 2008. Beyond case studies: Barriers to energy efficiency in commerce and the services sector. Energy Economics 30 (2): $449-464$.

Segal, David. 2009. Pillow fights at the Four Seasons. New York Times, June 28, 2009, Business: 1.

Sherwyn, David. 2010. The hotel industry seeks the elusive "green bullet." Cornell Hospitality Roundtable Proceedings 2 (1). http://www.hotelschool.cornell.edu/ $\mathrm{chr} / \mathrm{pdf} / \mathrm{showpdf} / \mathrm{chr} /$ roundtableproceedings/sustainabilitytopost.pdf?my_path _info $=$ chr/roundtableproceedings/sustainabilitytopost.pdf (accessed December 7, 2011).

Shrum, L. J., John A. McCarty, and Tina M. Lowrey. 1995. Buyer characteristics of the green consumer and their implications for advertising strategy. Journal of Advertising 24 (2): 71-82.

Swaminathan, Jayashankar M., Stephen F. Smith, and Norman M. Sadeh. 1998. Modeling supply chain dynamics: A multiagent approach. Decision Sciences 29 (3): $607-632$.

Tuttelman, Mathew. 2008. EnerNOC energy start-up presentation at Boston University School of Management. November 19.

Unsal, Hakan I., and John E. Taylor. 2009. Integrating agent-based simulation with game theory to investigate the hold-up problem in project networks. In Construction Research Congress proceedings: Building a sustainable future, ed. 
Samuel T. Ariaratnam and Eddy M. Rojas, 1280-1289. Reston, VA: American Society of Civil Engineers.

Verma, Rohit, Gary M. Thompson, and Jordan J. Louviere. 1999. Configuring service operations in accordance with customer needs and preferences. Journal of Service Research 1 (3): 262-274.

Zhang, Jie J., Nitin Joglekar, and Rohit Verma. 2011. Contract incentive design for environmental sustainability in service operations: A principal-agent analysis in the U.S. hospitality industry. Working paper. University of Vurmont.

Zhang, Jie J., Nitin Joglekar, and Rohit Verma. 2012. Pushing the frontier of sustainable service operations management: Evidence from U.S. h(s)itality industry. Journal of Service Management 23 (3): 377-399. 